\title{
Dynamics of Stock Prices and Market Efficiency
}

\author{
Antônio André Cunha Callado ${ }^{1}$, Carla Renata Silva Leitão ${ }^{2}$ \\ ${ }^{1}$ Full Professor, Programa de Pós-Graduação em Controladoria, Departamento de Administração, Universidade \\ Federal Rural de Pernambuco, Recife/Pernambuco, Brazil \\ ${ }^{2}$ Adjunt Professor, Programa de Pós-Graduação em Controladoria, Departamento de Administração, \\ Universidade Federal Rural de Pernambuco, Recife/Pernambuco, Brazil \\ Correspondence: Antônio André Cunha Callado, Programa de Pós-Graduação em Controladoria, Universidade \\ Federal Rural de Pernambuco, Recife/PE, Brazil, Rua Estrela, 203, apto 402, Parnamirim. CEP: 52.060-160, \\ Brazil.
}

Received: January 25, 2018

doi:10.5539/ibr.v11n6p29

\author{
Accepted: April 14, $2018 \quad$ Online Published: May 9, 2018 \\ URL: https://doi.org/10.5539/ibr.v11n6p29
}

\begin{abstract}
Over the last few decades, academic research on market efficiency has taken a leading position in the field of financial theories. The objective of this paper is to present contradictions within the evidence about market efficiency and discuss efficiency measurement as an emerging approach. The paper presents the evolution of research and also the lack of convergence between evidence provided by the literature and the lack of consistent arguments for explaining them. The paper also presents a framework that illustrates intermediate levels of efficiency and the first approach designed to measuring market efficiency. Finally the paper points out that divergences amongst the empirical evidence found in the literature should be considered as a key issue and further efforts should focus on specific conceptual elements inherent to its operationalization. Therefore, econometric models should not be given the exclusive responsibility of explaining market efficiency, nor possibility of incorporating alternative epistemological perspectives into the efficient / inefficient duality should be kept outside.
\end{abstract}

Keywords: market efficiency, partial efficiency, measurement of efficiency

\section{Introduction}

Over the last few decades, financial research has evolved significantly from empirical studies on the efficiency of stock markets, contributing to modern portfolio theory, investment analysis, risk management, and international integration of the capital markets. However, the evidence found in both international and Brazilian literature is not convergent with each other and its causes have been attributed to the methodological procedures, the time intervals investigated, the frequency of the series and the types of series used. The objective of this paper is to present contradictions among evidence about market efficiency and discuss an emerging approach for academic research in this field.

The theoretical relevance of the studies on market efficiency is related to understanding the behavior of the stock markets, as well as to the developments generated by the expansion of the scope of research in the area of finance. The Efficient Market Hypothesis (EMH) is certainly one of the most relevant investigative strands for the modern theory of finance. Its research has been boosted by both its theoretical perspectives and its practical applications.

Due to its importance, EMH has been extensively tested over the last decades. Comments on the conceptual components of EMH can be found in Malkiel (1992). For this author, a market is considered efficient if it is able to reflect all relevant information in the process of determining stock prices. A broad review of the main theoretical and empirical aspects related to market efficiency was elaborated by Fama (1970). For this author, in an efficient market, all available information will be fully reflected in stock prices and the proper operationalization of stock market research needs to consider it to be efficient and in balance.

Comments on this theoretical-empirical review can be found in Leroy (1976), who suggests a conceptual imprecision about market efficiency in which a market should be considered efficient when all the information needed to predict future stock prices is reflected in its current prices, rather than considering all available information. Although Fama (1976) corroborated this new definition, the original one presented in 1970 has been predominantly accepted and diffused within the literature. 


\section{Market Efficiency}

In the vast literature regarding market efficiency, early contributions to empirical studies on stock price behavior are attributed to Bachelier (1900), Cowles (1933), Working (1934), Williams (1938), Kendall (1953), Roberts (1959), Working (1960), Granger and Morgenstern (1963) and Samuelson (1965) (CAMPBELL; LO; MACKINLAY, 1997).

The EMH was mathematically formalized in the 1960s, through a model designed to represent the process by which time series of stocks prices would not present predictable patterns of behavior that could be successfully forecast considering only their past values. The contribution made by Samuelson (1965) is an important breakthrough for the theoretical notion about informational efficiency. This contribution was based on the understanding of efficiency stemming from the assertion that stock prices behave in a random manner. Comments that support this perspective can also be found in Ceretta (2001).

From this theoretical notion of efficiency, one can expect that successive changes in the prices of shares traded in an efficient stock market should behave independently from one another, and no investor could use such information (which is publicly available) to earn extraordinary future gains. Campbell, Lo and MacKinlay (1997) argue that changes in prices must be unpredictable but, in addition, prices must fully incorporate the expectations as well as the information available.

Given the assumption that any given stock market is considered efficient and in equilibrium, the expected financial returns (for a certain instant of time) arising from changes in stock prices should reflect all available relevant information up to that date. In a conceptually efficient stock market, no evidence should be found about serial relations between present and past returns, considering it would stand against unpredictability and independence and statistically significant autocorrelations could be characterized.

A detailed presentation of this conceptual expectation can be found in Cuthbertson and Nitzche (2004). If time series of stock returns have evidence of autocorrelation, EMH has been violated, since the error obtained may exert a predictive effect in relation to future returns. Fama (1991) goes even further on these matters, pointing out that market efficiency assumes that returns are unpredictable from past returns or any other past variables. If stock prices can be predictable (absolute or partially) through the use of available information, then EMH cannot be sustained because of the unequivocal inefficiency evidence found.

\section{Conceptual Dimensions on Market Efficiency}

A significant amount of the empirical research carried out to study EMH, as well as several theoretical constructs developed over the last three decades regarding the behavior of stock markets, has assumed that these markets can be efficient and therefore unexplored opportunities would be quickly disappearing. Market efficiency can be considered in different conceptual dimensions. Akhter and Misir (2005) and Simons and Laryea (2006) present the characteristics of the three conceptual dimensions associated with EMH as follows:

- Allocational efficiency;

- Operational efficiency;

- Informational efficiency.

The research carried out to focus on allocational efficiency seeks to analyze if the financial resources are allocated in projects that have more adjusted risk/return ratios. Operational efficiency research aims to analyze whether transactions are carried out quickly, correctly and with low acceptable cost. Research on information efficiency aims to analyze if the stock reflects all relevant available information into its prices. Informational efficiency has been the prevailing focus of research considered for empirical investigations on EMH.

Informational efficiency is characterized by Verma (2005) as the one that investigates the ability to predict future changes in stock prices based solely on information as related to the notion of efficiency. The analysis of this definition of informational market efficiency covers a judicious set of assumptions, as well as demands a sophisticated and robust methodological approach. Simons and Laryea (2006) present several considerations about the scope and diversity of topics contained in the financial literature from which it is argued that there is a tendency to choose informational efficiency when discussing market efficiency.

A contextualization of this conceptual perspective about international informational market efficiency can be found in Malliaris and Urrutia (2003). International market efficiency is presented as the one in which globally traded stock prices reflect all available information about world economic activity.

Commenting on the premises of stock price behavior in the context of an efficient stock market, Sharma (2006) points out that, among the general theoretical assumptions made, all traded shares in a given stock market should 
be almost perfect surrogates. The acceptance that all the shares traded in a stock market seem to be almost perfect surrogates of one another suggests that such market should present the following characteristics:

- Large number of traded shares;

- Significant amount of trade operations;

- Large number of both individual and institutional investors;

- Significant amount of financial resources;

- Ensure symmetrical disclosure of information;

- Equilibrium.

If any given individual stock traded in a stock market is to behave in a manner which is consistent with the notion of efficiency and market equilibrium, it must be uninterruptedly considered for trading over a certain period of time. It is necessary to emphasize that the presence of these characteristics is not enough to assure the acceptance of the EMH, nor to eliminate the need to carry out empirical investigation designed to corroborate it or to refute it.

\section{Characteristics of Returns}

Within the various research operational possibilities, the observable returns in a stock market can refer to different types of assets, namely:

- Individual stock returns;

- Market index returns;

- Portfolio returns.

The literature presents two main alternative operational methodologies for the calculation of returns. The first one is responsible for calculating simple returns. The second one operationalizes the calculation of compound returns.

The simple return calculation is operationalized through a conventional formula designed to represent its rate of change, highlighted below:

$$
\mathrm{R}_{\mathrm{t}}=\frac{P_{t}-P_{t-1}}{P_{t-1}}
$$

Where,

$R-$ Return

$P$ - Stock price

$t-$ Index of time

The calculation of compound returns is operationalized through the representation of stock prices in logarithm. This approach can be accomplished through two different formulas, namely:

$$
\mathrm{R}_{\mathrm{t}}=\log P_{t}-\log P_{t-1}
$$

Or 


$$
\mathrm{R}_{\mathrm{t}}=\log \left(\frac{P_{t}}{P_{t-1}}\right)
$$

Where,

$R-$ Return

$P$ - Stock price

$t$ - Index of time

In Costa Jr. and O'Hanlon (2000) and in Dritsaki (2005) are presented several arguments that support the adoption of returns calculated through the procedure expressed in logarithm as the most likely to be normally distributed. Sharma (2006) adds emphasizing that the use of this approach reduces the bias arising from changes in stock prices due to their increasing. From this expectation, it is assumed that the various parameters calculated have robustness.

When adopting a specific methodology for the calculation of returns, it is necessary to consider some operational peculiarities inherent to the periodicity of the calculated returns or the type of financial asset investigated. In this sense, several alternative procedures for the calculation of individual stock returns and stock market indices can be pointed out in comparison to the calculation of the return regarding stock portfolios. Taylor (2005) points out that a daily return from individual stocks (similarly to daily returns on market indices), is rarely in the range of $-10 \%$ to $10 \%$, and therefore, it would be surprising if some important conclusion depended on the choice of the returns calculating method. Given the magnitude of daily returns, the results obtained tend to behave indifferently in relation to the calculation method used.

In the case of stock portfolios returns, specificities deriving from each of the alternative modalities can be found. Campbell, Lo and MacKinlay (1997) present arguments about them. For these authors, the simple return of a stock portfolio is obtained by summing the various simple returns inherent to each of the individual shares proportionally weighted, unlike the composite return of a stock portfolio that does not have this same mathematical property, since that the log of a sum is not equal to the sum of logarithms.

The acceptance of market efficiency implies that the series of returns follow a Random Walk trajectory, unlike the acceptance of the influence of exogenous factors on the process of future returns. The absence of unpredictability on a series of returns is presented by Robinson (2005) as a factor that contributes to the reduction of its amplitude and its liquidity, since investors unfamiliar with its operation will refuse to participate in operations in such markets. Another relevant problem is presented by Ojah and Karemera (1999). For these authors, the presence (or absence) of the properties of a Random Walk trajectory in the series of stock returns has important implications for trading strategies, as well as for pricing models.

The acceptance of EMH does not formally require that stock market prices be the same as the baseline values, but it does require that the discrepancies between these values are not biased. To the extent that these discrepancies are random, the traded shares may be undervalued or overvalued at any instant of time.

Another relevant construct for the understanding of the market informational efficiency is associated with future prices forecast errors. In Cuthbertson and Nitzche (2004), references are made about the prediction errors inherent characteristics (zero mean and not correlated with any information that was available at the instant of time in which the forecast was made), assuming the following representation:

$$
P_{t+1}=E_{t} P_{t}+\varepsilon_{t+1}
$$

Where,

$P$ - Price

$E$ - Predictability factor

$\varepsilon$ - Error

$t$ - Index of time 
Through this model, it can be observed that the future price is presented as a function of the predicted price at the previous time instant added to the error. Ferson, Heuson, and Su (2000) present a focused discussion on predictive capacity over future returns by comparing regressions that consider daily returns relative to regressions that consider returns over longer time intervals. According to these authors, the $\mathrm{R}^{2}$ values obtained were larger, because the expected returns are more persistent than the returns themselves.

This distinction is important because it reveals the influence of particularities inherent to returns, especially considering the presence of long-term structural factors that will exert an influence on returns more consistently than only the daily variations in the negotiation process and that may be used to predict future returns.

Regarding the possibility of using past returns to predict future returns, Costa Jr., Leal and Lemgruber (2000) point out that the predictability of future returns may be due to three distinct factors and that each of these factors has its own characteristics and should be considered as dimensions, independent of each other, but all of them being capable of causing disruption of EMH:

- Rational changes in market expectations;

- Inefficiency;

- Anomaly.

Rational changes on market expectations can be generated from abrupt paradigmatic ruptures. Inefficiency is understood as the possibility of obtaining extraordinary gains based on available information. Anomalies can also make extraordinary gains. Anomaly is defined by Neves and Leal (2004) as being the statistically significant difference between the observed average return of an asset, associated to certain specific characteristics, and the expected return through a specific pricing model for this same asset.

It should be emphasized that the distinction between inefficiency and anomaly has been no easy task to be made. The distinction between anomaly and inefficiency is presented by Robinson (2005) as an issue open to discussion among academics and that the literature still lacks clearer definitions of market imperfection and market anomaly.

Several definitions of anomalies can be found in the literature, some of which contain different terminologies. For Cuthbertson and Nitzsche (2002), anomalies are rational investors' irrationalities or inability to equate fair value with the effective price. For both Bodie, Kane and Marcus (2000), and Neves and Leal (2004), anomalies are considered as evidence inconsistent with EMH, as risk factors can affect the return of assets and be used as a basis for the development of investment strategies that generate superior returns.

Inefficiency is associated with the possibility of identifying temporary opportunities of higher gains by some investors to the detriment of the others, while anomaly refers to the identification of some characteristic (or risk factor) that can be considered for the elaboration of investment strategies that does not disappear or even has regularity.

In essence, an anomaly should be considered as market inefficiency, as it violates the notion of randomness and unpredictability about future returns, but it contains elements unrelated to the assumptions of market rationality. On the other hand, inefficiency can not be conceptually considered as an anomaly because, although it is a violation of the notion of randomness and unpredictability about future returns, it tends to disappear, based on the rational decisions of market agents.

\section{Operationalizing Research Regarding Market Efficiency}

The process of operationalizing the analysis of market efficiency is done through several tests designed specifically to corroborate/refute EMH, considering the different levels of information efficiency, originally classified by Fama and French (1988) and further elaborated by Fama (1991).

The operationalization considers that stock markets can be efficient in different ways, depending on the speed at which the information is incorporated into the negotiated stock prices, being efficient in all weak, semistrong and strong forms. The different levels of efficiency proposed by this classification consider different operational attributes related to their respective capacity to maintain informational efficiency.

As the classification of market efficiency levels considers the full incorporation of information from different dimensions, it is reasonable to assume that the various efficiency tests developed over the last decades are classified through this same reference. Fama (1991) emphasizes that the tests designed to analyze the different levels of efficiency have different characteristics. The market efficiency tests are grouped as follows: Efficiency tests of the weak form (predictability tests); Tests of efficiency of the semistrong form (tests of events); Strong form efficiency tests (private information tests). In order to test EMH at any of the three efficiency levels, it is 
necessary to consider the dynamics of the incorporation of new information by stock prices based on the specificities of each one of them.

The various tests presented in the literature are designed to evaluate specific circumstances that need to be adequately considered, under penalty of generating spurious and meaningless results. Comments on the lack of consensus on the accuracy of the various efficiency tests in terms of their ability to accurately measure the efficiency of a given stock market can be found in Akinkugbe (2005).

Weak form market efficiency tests are known as returns predictability tests. In Elton et al. (2004) references can be found by which it is emphasized that predictability tests consider historical stock price series to investigate their predictive ability on future returns.

Predictability tests analyze the ability to disseminate information within a stock market. Bodie, Kane and Marcus (2000) find it improbable that, given the possibility of significant evidence on the predictability of future prices, other investors do not have full access to this information.

The main predictability tests cited by Campbell, Lo and MacKinlay (1997) as theoretically plausible to evaluate Random Walk trajectories constructed from historical series of returns are the following: Sequence and reversals test; Tests of runs (runs test); Technical analysis test; Filter test (filter rule test); Autocorrelation coefficients test; Variance ratio test.

All of these tests that investigate EMH in its weak form consider the possibility of finding evidence that can refute the properties of a Random Walk trajectory and, therefore, reject it. Among them, the autocorrelation test has been widely used to evaluate the weak form of market efficiency. Seminal works, such as Fama (1970), Leroy (1973) and Levich (1979), French and Roll (1986), Fama and French (1988) and Lo and MacKinley (1988), report empirical evidence for autocorrelation of returns of stocks. However, its findings have not been considered significant enough to reject EMH because of its low intensity.

Lo and MacKinlay (1999) apud Malkiel (2003) state that the short-run autocorrelation relative to the time series of stock prices is different from zero and that the existence of a reasonable number of price movements in the same direction rejects the hypothesis that these price series are truly random. Laurence, Cai and Qian (1997) point out particularities about the rejection of evidence of autocorrelation as evidence contrary to EMH, emphasizing that, as the size of the time interval in which autocorrelation is found increases, this evidence will imply a violation in the market efficiency.

In Fama (1991) an analysis is presented in which the literature does not consider evidence of small autocorrelation in daily and weekly series of stock returns to be interpreted as violation of EMH, since they are of low intensity (approximately 1\% for individual stocks) and that, therefore, they have not been considered sufficient to invalidate the acceptance of this hypothesis.

Assuming the notion of efficiency proposed by EMH, in which prices should reflect all available information, this test should be appropriate to assess efficiency, since future returns are unpredictable from past returns and have already incorporated variations to the other variables.

Market efficiency tests designed for semistrong form are known as event tests. The main event tests are the following: Ad tests (announcements); Tests of non-anticipated economic news.

These tests consider the possibility of finding evidence that can capture the speed at which stock prices incorporate new information, so that it is not possible to evidence extraordinary gains from ads (mergers, profits, etc.) or that they incorporate information (abrupt changes in the interest rate or exchange rate, fines received or audits).

Comments on the operationalization of efficiency tests in semifortex form can be found in Elton et al (2004). The tests of events are presented by these authors as those that aim to investigate if there is the possibility of exceptional gains, considering the speed of the incorporation of new information to the stock prices.

In Fama (1991), the application and relevance of event studies, as well as references inherent to the expansion of their scope of research (widely verified in the literature over the last 20 years) and the identification of clearer empirical evidence on the market efficiency.

Other arguments that justify the applicability of event studies for the purpose of measuring abnormal changes in publicly traded stock prices, as well as demonstrating that this is one of the most widespread techniques for examining the impact of certain facts on stock prices, may be found in Wells (2004).

Perobelli and Ness Jr. (2000) present a conceptual discussion about the central idea common to all efficiency tests in the semifortex form in which anomalous patterns on returns are sought in the days next to the disclosure 
of the event that may be related to it. The most common limitations are derived from the time instants of the events, the sample sizes and the measurement of the effects.

Strong form market efficiency tests are referred to as informational symmetry tests. The main tests of informational symmetry are the tests of negotiation and the tests on analysts' forecasting. Elton et al. (2004) point out that these tests consider market efficiency at the strong level and seek to investigate whether insiders can make extraordinary profits through the use of sensitive information.

In Syed, Liu and Smith (1989) references are found on the inherent expectation to market efficiency in the strong form, in which EMH assumes that all information (public or private) is disseminated so rapidly in stock prices that no investor can use them to obtain abnormal returns.

A particular dimension on strong efficiency form can be found in Laird (1995). For this author, if one makes resource allocation decisions in the stock market that are based on undisclosed information, other investors are able to identify this movement and follow it so that stock prices rapidly incorporate such events.

These tests consider the possibility of finding evidence that can capture the misuse of information that is not available to the general public (inside information), as well as tests on analysts' opinion (selection and survival bias).

Wong, Cheung and $\mathrm{Wu}$ (2000) present comments on the methodological procedures inherent to the market-efficiency test in its strong form. For these authors, this test consists of an event study focused on notifications of operations performed by directors and executives within the stock market in search of abnormal returns on the days immediately before and after the actual execution of the transaction. Taking into account each of the efficiency tests individually, certain aspects of the stock market are considered with more emphasis to the detriment of the others, since it is difficult to evaluate all the nuances referring to EMH through a single test.

\section{Discrepancies Among Empirical Evidence}

The evidence found in the literature demonstrates that there is no clear convergence between the results obtained on EMH. Sadique and Silvapulle (2001) present a systematization of the origins of these discrepancies, pointing out that the results obtained have been dependent on the following aspects: methodologies applied; period of time considered for data gathering; frequency of the time series; type of time series considered into the analysis. Frequently these factors have been pointed out as the cause of this antagonism among results, without presenting consistent arguments that are able to explain it.

Other factors may be directly associated with the causes of antagonism in empirical evidence, such as the mathematical models used, the use of market indices as proxies, the differences between structures of the various stock markets and restrictions to the dual approach (efficient market / inefficient market).

In commenting on evidence provided by the literature that point to slow adjustments in stock prices as evidence contrary to EMH, Fama (1998) points out that they are sensitive to different mathematical models and they shouldn't be considered as sufficient to support a more consistent concept of market inefficiency. In this same sense, Kamara (1982) apud Neftci and Policano (1984) and Vives (1995) emphasize that the empirical investigations carried out have been predominantly considering the use of linear models that may not faithfully represent the behavior of the players that operate in the market.

Even considering only the previous research that adopted similar methodological procedures, still the results diverge among one another. These existing contradictions amongst the evidence presented by the international literature on EMH may be associated with structural deficiencies in the stock markets that have not been yet captured by the widely used linear econometric models.

Another key factor that may be associated with this antagonism is the use of market indexes as proxies that represent the behavior of their respective stock markets (see Abdullah and Hayworth, 1993; Laurence, Cai and Qian, 1997; Kwon, Shin and Bacon, 1997, Chen et al., 1998, and Chen, Firth and Rui, 2001, and Chen et al., 1998, Tsoulakas and Sil, 1999, Mavrides, 2000 and Dritsaki, 2005; Sharma, 2006). Despite all efforts to provide understanding of stock markets efficiency, the contribution to the literature given has been limited, since their results present significant discrepancies.

The importance of the stock markets structure is also an element which is poorly considered in this discussion. From the initial propositions postulated by the Capital Asset Pricing Model (CAPM), proposed by Sharpe (1964), as well as by the Arbitrage Pricing Theory (APT), proposed by Ross (1976), the equilibrium models have been used as methodologies to analyze the efficiency of stock markets without considering any consistent theoretical arguments 
that questioned the need for adjustments (or even limitations) to the applicability of these models in stock markets that have different development statuses. This same reasoning can be attributed to the time series of individual stock returns.

Conflicting evidence from undeveloped stock markets could be considered as expected. Results obtained from efficiency analysis of the Brazilian stock market have been broadly attributed to the periods of time investigated or to the samples of stocks considered. Leal and Amaral (1990) describe several key points about informational efficiency of the Brazilian stock market in comparison to the behavior that is expected from developed stock markets, particularly low liquidity, a high concentration of trading volume in a few stocks, small number of players and poor operational regulation.

Even among stock markets with the same developmental status, different evidence can be found. Results of EMH investigations carried out in the context of undeveloped markets can be found in Muradoglu, Taskin and Bigan (2000) and Doong, Yang and Wang (2005). These results are not homogeneous for all markets investigated and do not have consistencies between them. The evidences found suggest that the undeveloped markets, when compared, have specificities and react differently in relation to the explanatory variables used.

Comments on this limitation can be found in Dritsaki (2005). For this author, the contradictory results obtained in investigations carried out in the scope of the undeveloped stock markets may be due to the following factors: Periods of time investigated; Instability occurring in these markets.

Finally, another relevant aspect to be considered is associated with the limitations and questions presented in the literature that are inherent to the acceptance of the traditional dichotomy attributed to EMH (efficient/inefficient). This dichotomy can hardly be sustained, since the notion of partial efficiency seems to be more appropriate to reflect the reality of stock markets (see Fama, 1991, Fama 1998, Farmer and Lo 1999).

\section{A New Focus for Market Efficiency}

Over the last 20 years, discussion on intermediate states of efficiency can be found in the literature. Within it, several arguments about the practical and conceptual constraints on EMH consider as being more plausible that markets are not fully efficient or fully inefficient. Malkiel (2003) points out that the acceptance of EMH in its absolute form has been reduced due to several evidences that have supported the expectation that the prices of the shares are considered as partially predictable. Several arguments have been addressed to support the expectations inherent to accepting an intermediate notion of efficiency, termed partial market efficiency.

In Alkinkugbe (2005), the conceptual notion of partial efficiency is presented as being responsible for the contextualization of a theoretical reference that is opposed to the traditional notion of absolute efficiency (or inefficiency). Robinson (2005) emphasizes that the simple assertion that a market is partially efficient does not add significant meaning to the discussion, and it is necessary to provide clear definitions on the aspects associated with partial efficiency. He further emphasizes that these definitions should not be tied exclusively to the concept of the Random Walk trajectory.

This conceptual perspective on partial market efficiency admits the possibility of an intermediate status, between inefficient markets and efficient markets. The notion of partial efficiency is presented by Farmer and Lo (1999) as being more advantageous than the notion of absolute efficiency (or inefficiency). For these authors, partial efficiency is one of the future research perspectives on market efficiency, and they consider that the partial efficiency measurement can be used to compare the efficiency intensity of different stock markets.

In these terms, the deepening of focused discussions on both the different methodological and conceptual approaches to market efficiency is necessary to give a more consistent epistemological support to the numerous mathematical models used. However, the current efforts haven't been enough to elucidate and sediment the research field in which market efficiency is embedded.

The literature does not yet present a specific definition of partial market efficiency. On the other hand, conjectures arising from the difficulty of accepting the absolute efficiency inherent to the classical notion of market efficiency advocated by EMH, stock markets hardly should be considered as fully efficient or completely inefficient.

Since the definition of market efficiency is broadly accepted, partial market efficiency could be approached from this starting point. Callado (2009) presents a four-step approach designed for measuring stock markets partial efficiency, considering time series from all traded individual stocks, so that each individual stocks could be ranked into five compliance levels.

These compliance levels, presented in Figure 1, represent the adherence of returns time series regarding their compliance to the notion of market efficiency through the following of four steps, based on Granger's Causality 
(1969): Length of uninterruptness; Unit root; Co-integration between returns time series and exogenous variables; Causality test between returns time series and exogenous variables.

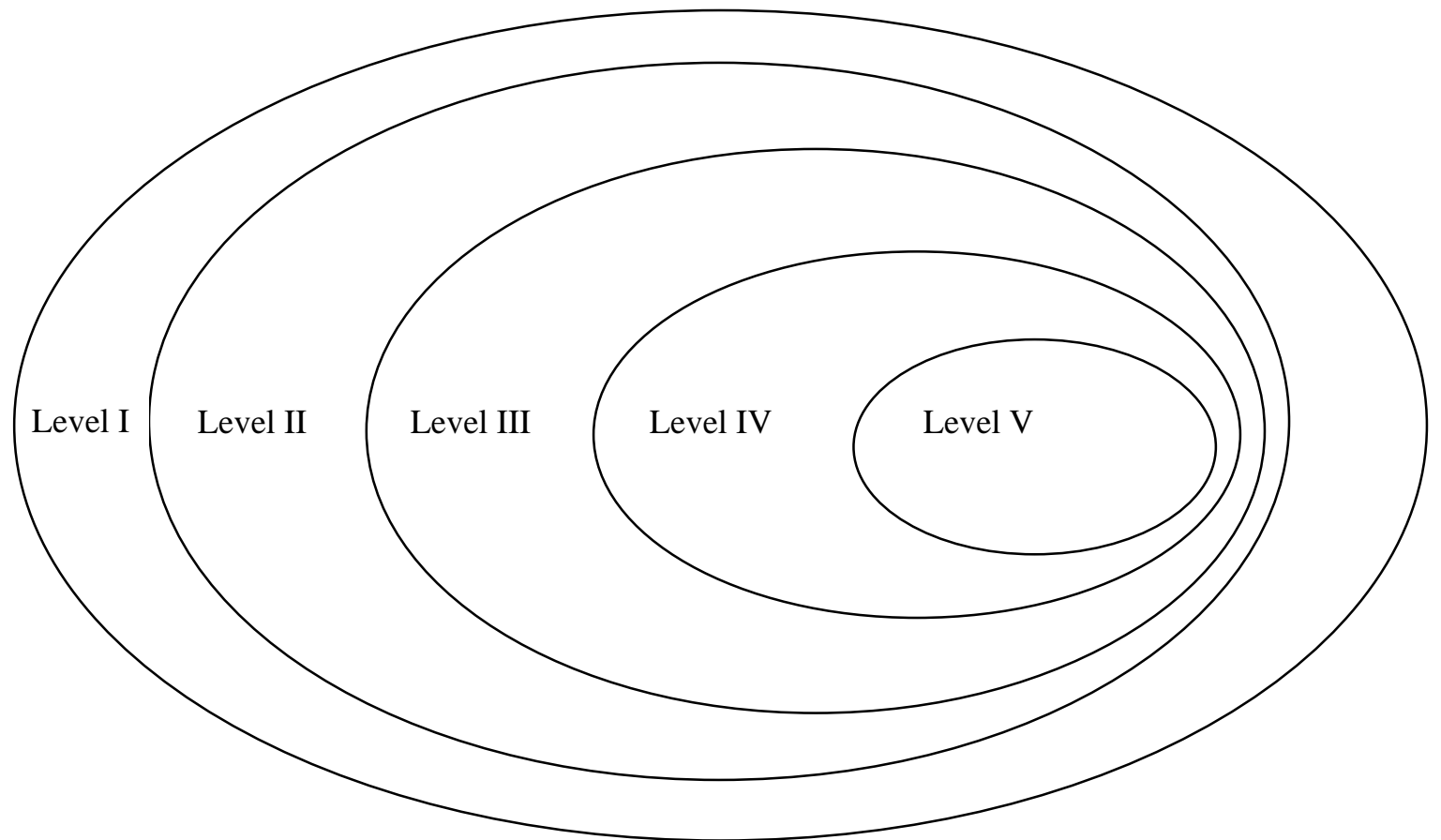

Figure 1. Level of compliance of individual stock returns time series with the notion of market efficiency

\section{Source: Callado (2009)}

The first step analyzes the composition of returns time series from all traded individual stocks in search of those that have an uninterrupted sequence of data. The second step analyzes stationarity of returns time series, as well as time series of an exogenous economic variable, such as interest rates and inflation. The third step analyzes the significance of co-integration relationships between the returns times series and the exogenous economic variable. The fourth step analyzes the significance of causality relationships between the returns times series and the exogenous economic causality variable. This step aims to investigate the presence of causal relationships between the returns times series of individual stocks and the exogenous variable considered.

This approach was considered as the basis for proposing different levels of compliance for individual stocks regarding the notion of efficiency and each step is associated with a specific level of compliance status. The greater the number of steps exceeded by a certain individual stock, the greater is its level of compliance with respect to the notion of efficiency.

\section{Conclusions}

In view of the numerous reflections presented on the epistemology of the prevailing investigative praxis in the field of market efficiency, it is necessary to develop efforts aimed at understanding the causes of the contradictions existing within the literature. There seems to be no doubt about the latent uncertainties inherent to the operational issues presented and discussed.

The predominant methodological approach to market efficiency, considering it as a hypothesis to be tested, has provided numerous advances in the mathematical modeling used, mainly after the emergence and improvement of computational tools, as well as of the various databases available.

On the other hand, the influence of important operational aspects, such as how the historical series of returns are generated, along with their specific aspects (individual stock returns, stock returns, market index returns) and scales of data frequency (daily, monthly, etc.), on the empirical results have been shortly discussed.

It should be noted that the divergences amongst the empirical evidence found in the literature constitute a clear signal that this field of research needs efforts focused on specific conceptual elements inherent to its operationalization. 
In these terms, econometric models should not be given the exclusive responsibility of solving the problems inherent to scientific research on market efficiency, nor can we deny the possibility of incorporating alternative epistemological perspectives into the efficient / inefficient duality that underlies the hypothesis to be tested.

\section{References}

Abdullah, D. A., \& Hayworth, S. C. (1993). Macroeconometrics of stock price fluctuations. Quarterly Journal of Business and economics, 32(1), 50-67.

Akhter, S., \& Misir, M. A. (2005). Capital markets efficiency: evidence from the emerging capital market with particular reference to Dhaka stock exchange. South Asian Journal of Management, 12(3), 35-51.

Akinkugbe, O. (2005). Efficiency in Botswana stock Exchange: An empirical analysis.Cambridge. The Business Review, 4(2), 233-230.

Bachelier, L. Theory of speculation (1900). In COOTNER, P. (1964). The Random Character of Stock Market Prices. Cambridge: Massachusetts Institute of Technology Press.

Bodie, Z., Kane, A., \& Marcus, A. J. (2000). Fundamentos de investimentos. Porto Alegre: Bookman.

Callado, A. A. C. (2009). Eficiência do mercado acionário brasileiro: Retorno das ações negociadas na Bovespa, variáveis macroeconômicas, causalidade e fatores condicionantes. Ph.D. Dissertation. Programa de Pó-Graduação em Administração. Universidade Federal de Pernambuco.

Campbell, J. Y., LO, A., \& W; Mackinlay, A. C. (1997). The econometrics of financial markets. New Jersey: Princeton.

Ceretta, P. S. (2001). Comportamento das variações de preços nos mercados de ações da América Latina. In: ANAIS DO XXV ENANPAD. ANPAD. Campinas.

Chen, G., Firth, M., \& Rui, O. M. (2001). The dynamic relation between stock returns, trading volume and volatility. The Financial Review, 36(3), 153-174. https://doi.org/10.1111/j.1540-6288.2001.tb00024.x

Chen, S. J. Hsieh, C., Vines, T. W., \& Chiou, S. N. (1998). Macroeconomic variables, firm-specific variables and returns to REIT's. The Journal of Real State Research, 16(3), 269-277.

Costa Jr, N. C. A., \& O'hanlon, J. (2000). O efeito tamanho versus o efeito mês-do-ano no mercado de capitais brasileiro: Uma análise empírica. In COSTA Jr; N.C.A., LEAL; R.P.C., \& LEMGRUBER, E.F. (ORG). Mercado de capitais. São Paulo: Atlas.

Costa Jr; N. C. A., Leal; R. P. C., \& Lemgruber, E. F. (2000). Parte III - Anomalias e eficiência. In COSTA Jr; N. C. A; LEAL; R. P. C; LEMGRUBER, E. F. (ORG). Mercado de capitais. São Paulo: Atlas.

Cowles, A. (1933). Can stock markets forecasters forecast? Econometrica, 1(3), 309-324. https://doi.org/10.2307/1907042

Cowles, A., \& Jones, H. (1937). Some a posteriori probabilities in stock market action. Econometrica, 5(3), 280-294. https://doi.org/10.2307/1905515

Cuthbertson, K., \& Nitzche, D. (2004). Quantitative financial economics. 2ed. West Sussex: Wiley.

Doong, S., Yang, S., \& Wang, A. T. (2005). The dynamic relationship and pricing of stocks and exchange rates: Empirical evidence from Asian Emerging markets. Journal of American Academy of Business, 7(1), 118-123.

Dritsaki, M. (2005). Linkage between stock market and macroeconomic fundamentals: Case study of Athens stock exchange. Journal of Financial Management and Analysis, 18(1), 38-47.

Elton, E. J., Gruber, M. J., Brown, S. J., \& Goetzmann, W. N. (2005). Moderna teoria de carteiras e análise de investimentos. São Paulo: Atlas.

Fama, E. (1970). Efficient capital markets: A review of theory and empirical work. Journal of Finance, 25(2), 383-417. https://doi.org/10.2307/2325486

Fama, E. (1976). Efficient capital markets: Reply. The Journal of Finance, 31(1), 139-141. https://doi.org/10.1111/j.1540-6261.1976.tb03204.x

Fama, E. (1991). Efficient capital markets II. Journal of Finance, 46(5), 1575-1617. https://doi.org/10.1111/j.1540-6261.1991.tb04636.x

Fama, E. (1998). Market efficiency, long-term returns and behavioral finance. Journal of Financial Economics, 49, 283-306. https://doi.org/10.1016/S0304-405X(98)00026-9 
Fama, E., \& French, K. R. (1988). Dividend yields and expected stock returns. Journal of Financial Economics, 22(1), 3-25. https://doi.org/10.1016/0304-405X(88)90020-7

Farmer; J. D., \& Lo, A. W. (1999). Frontiers of finance: Evolution and efficient markets. Proceedings of the National Academy of Sciences of The United States of America, 96(18), 9991-9992. https://doi.org/10.1073/pnas.96.18.9991

Ferson, W. E., Heuson, A., \& Su, T. (2005). Weak-form and semi-strong form stock return predictability revisited. Management Science, 51, 1582-1592. https://doi.org/10.1287/mnsc.1050.0396

French, K. R., \& Roll, R. (1986). Stock return variances: the arrival of information and reaction of traders. Journal of Financial Economics, 17(1), 5-26. https://doi.org/10.1016/0304-405X(86)90004-8

Granger, C. W. J. (1969). Investigating Causal Relations by Econometric Models and Cross-Spectral Methods. Econometrica, 37(3), 424-438. https://doi.org/10.2307/1912791

Granger, C. W. J., \& Morgenstern, O. (1963). In Cootner. 1964. Spectral analysis of New York stock market prices.

Kamara, A. (1982). Issues in future markets: A survey. Journal of Future Markets, 2(3), 261-294. https://doi.org/10.1002/fut.3990020306

Kendall, M. G. (1953). The analysis of economic time series. Part I - Prices. Journal of the Royal Statistical Society, 116(1), 11-34. https://doi.org/10.2307/2980947

Khan, M. A., \& Sun, Y. (1997). The Capital Asset pricing Model and Arbitrage Pricing Theory: A unification. Economic Sciences, 94(8), 4229-4232. https://doi.org/10.1073/pnas.94.8.4229

Kwon, C. S., Shin, T.S., \& Bacon, F. W. (1997). The effect of macroeconomic variables on stock market returns in developing markets. Multinational Business Review, 5(2), 119-126.

Laird, M. J. (1995). Insider trading. Managerial Auditing Journal, 10(5), 16-26. https://doi.org/10.1108/02686909510087946

Laurence, M., Cai, F., \& Qian, S. (1997). Weak-form efficiency and causality tests in Chinese stock markets. Multinational Finance Journal, 1(4), 291-307. https://doi.org/10.17578/1-4-3

Leal, R. P. C., \& Amaral, A. S. (1990). Um momento para o insider trading: o período anterior ao anúncio de uma emissão pública de ações. Revista Brasileira do Mercado de Capitais, Rio de Janeiro, 15(41), 21-26.

Leroy, S. F. (1973). Risk aversion and the Martingale property of stock returns. International Economic Review. 14(2), 436-446. https://doi.org/10.2307/2525932

Leroy, S.F. (1976). Efficient capital markets: Comment. The Journal of Finance, 31(1), 139-141. https://doi.org/10.1111/j.1540-6261.1976.tb03204.x

Levich, R. M. (1979). . On efficiency of markets for foreign exchange. In Dornbusch, R e Frenkel, J (Ed). International Economic Policy. Baltimore: John Hopkins Press.

Lo, A., \& Mackinlay, A. G. (1988). Stock market prices do not follow random walks: Evidence of simples specification tests. The Review of Financial Studies, 1(1), 41-66. https://doi.org/10.1093/rfs/1.1.41

Lo, A., \& Mackinlay, A. G. (1999). A non-random walk down Wall Street. Princeton. Princeton University Press.

Malkiel, B (2003). The Efficient market hypothesis and its critics. The Journal of Economic Perspective, 17(1), 59-82. https://doi.org/10.1257/089533003321164958

Malkiel, B. (1992). Efficient market hypothesis. In Milgate, P. M, Eatwell (Ed) New Palgrave Dictionary of Money and Finance. London: Macmillan.

Malliaris, A. G., \& Urruitia, J. L. (2003). The Efficient market hypothesis and its critics. The Journal of Economic Perspective, 17(1), 59-82. https://doi.org/10.1257/089533003321164958

Mavrides, M. (2000). Granger causality tests of stock returns: The US and Japanese stock markets. Managerial Finance, 26(12), 13-25. https://doi.org/10.1108/03074350010767016

Muradoglu, G., Taskin, F., \& Bigan, I. (2000). Causality between stock returns and macroeconomic variables in emerging markets. Russian and East European Finance and Trade, 36(6), 33-53.

Neves, M. B. E. das, \& Leal, R. P. C. (2004). Existem relações entre o crescimento do PIB brasileiro e os efeitos tamanho, valor e momento? In: ANAIS DO XXV ENANPAD. ANPAD. Campinas. 
Ojah, K., \& Karemera, D. (1999). Random walk and market efficiency tests of Latin American emerging equity markets: A review. The financial review, 34(2), 57-72. https://doi.org/10.1111/j.1540-6288.1999.tb00454.x

Perobelli, F. F. C., \& Ness jr, W. L. (2000). Reações do Mercado Acionário a Variações Inesperadas nos Lucros das Empresas: um Estudo sobre Eficiência Informacional no Mercado Brasileiro. In: ANAIS DO XXVI ENANPAD. ANPAD: Florianópolis.

Roberts, H. (1959). Stock market patterns and financial analysis: Methodological suggestions. Journal of Finance, 14(1), 1-10.

Robinson, J. (2005). Stock price behavior in emerging markets: Tests for weak form market efficiency on the Jamaica stock exchange. Social and Economic Studies, 54(2), 51-69.

Ross, S. A. (1976). The arbitrage theory of capital asset pricing. Journal of Economics Theory, 13, 341-360. https://doi.org/10.1016/0022-0531(76)90046-6

Sadique, S., \& Silvapulle, P. (2001). Long-term memory in stock market returns: International evidence. International Journal of Finance \& Economics, 6(1), 59-67. https://doi.org/10.1002/ijfe.143

Samuelson, P. (1965). Proof that properly anticipated prices fluctuate randomly. Industrial Management Review, 6(2), 41-49.

Sharma, L. J. K. (2006). Stock price changes in trading volume in context of India's economic liberalization and its emerging impacts. Finance India, 20(1), 33-53.

Sharpe, W. F. (1964). Capital asset prices: A theory of market equilibrium under conditions of risk. Journal of Finance, 19(3), 425-442.

Simons, D., \& Laryea, S. A. (2006). The efficiency of selected African markets. Finance India, 20(2), 553-571.

Syed, A. A., Liu, P., \& Smith, S. D. (1989). The exploitation of inside information at the Wall Street Journal: A test of $\begin{array}{lllll}\text { strong form efficiency. The Financial Review, 24(4), 567-579. } & \text {. }\end{array}$ https://doi.org/10.1111/j.1540-6288.1989.tb00361.x

Taylor, S. J. (2005). Asset price dynamics, volatility and prediction. New Jersey: Princeton.

Tsoukalas, D., \& Sil, S. (1999). The determinants of stock prices: Evidence from the United Kingdom stock market. Management Research News, 22(5), 1-14. https://doi.org/10.1108/01409179910781652

Verma, A. (2005). A study of the weak form informational efficiency of the Bombay stock market. Finance India, 19(4), 1421-1424.

Vives, X. (1995). Short-term investment and the informational efficiency of the market. The Review of Financial Studies, 8(1), 125-160. https://doi.org/10.1093/rfs/8.1.125

Weels, W. H. (2004). A beginner's guide to event studies. Journal of Insurance Regulations, 22(4), 61-70.

Williams, J. B. (1938).. The theory of investment value. Cambridge: Harvard U. Press.

Wong, M. C., Cheung, Y. L., \& Wu, L. (2000). Insiders trading in the Hong Kong stock market. Asia-Pacific Financial Markets, 7(3), 275-288. https://doi.org/10.1023/A:1010009016980

Working, H. (1934). A random-difference series for use in the analysis of time series. Journal of American Statistic Association, 39(185), 11-24. https://doi.org/10.1080/01621459.1934.10502683

Working, H. (1960). Note on the correlation of first differences of averages in a random chain, 28(4), 916-918.

\section{Copyrights}

Copyright for this article is retained by the author(s), with first publication rights granted to the journal.

This is an open-access article distributed under the terms and conditions of the Creative Commons Attribution license (http://creativecommons.org/licenses/by/4.0/). 